\title{
Pengaruh Kualitas Pelayanan Pada Kepuasan Pelanggan Mabar \& Game Coffee
}

\author{
Rosiana Andhikasari \\ Universitas Bina Sarana Informatika, \\ rosiana.ror@bsi.ac.id
}

\begin{abstract}
Abstrak
Bisnis kuliner berupa café yang menjamur saat ini membuat para pemilik usaha berfikir keras untuk membuat café miliknya berbeda dengan yang lain sehingga dapat menarik minat pelanggan untuk datang, salah satunya pada Mabar \& Game Coffee. Peneliti ingin melihat apakah ada pengaruh antara kualitas pelayanan pada kepuasan pelanggan di Mabar \& Game Coffee. Penelitian ini memakai metode penelitian kuantitatif deskriptif dengan variabel $\mathrm{X}$ terdiri dari, variabel $\mathrm{X} 1$ adalah identitas fisik, variabel $\mathrm{X} 3$ adalah manajemen organisasi, variabel $\mathrm{X} 2$ adalah identitas non fisik, variabel X5 adalah aktivitas dan pola hubungan, variabel X4 adalah kualitas hasil, dan variabel Y adalah kepuasan pelanggan. Teknik analisis data yang digunakan yaitu regresi linier berganda, penghitungan hipotesis menggunakan uji $F$ dan uji $t$ dimana uji $F$ adalah untuk mengetahui pengaruh simultan antara variable $\mathrm{X}$ ke $\mathrm{Y}$, sedangkan uji $\mathrm{t}$ untuk mengetahui pengaruh secara parsial dari variable $\mathrm{X}$ ke $\mathrm{Y}$. dari hasil penghitungan menggunakan SPSS, didapatkan hasil bahwa variable $\mathrm{X}$ yang terdiri dari identitas fisik, aktivitas dan pola hubungan, kualitas hasil, manajemen organisasi, identitas non fisik memiliki pengaruh secara simultan terhadap variabel Y yaitu kepuasan pelanggan. Sedangkan dari penghitungan menggunakan uji t ditemukan bahwa identitas non fisik merupakan variabel yang paling dominan, sehingga menurut pelanggan, identitas non fisik yang dimiliki oleh Mabar \& Game Coffee sangat mempengaruhi kepuasan mereka.
\end{abstract}

Kata kunci: kualitas pelayanan, kepuasan pelanggan, cafe

\begin{abstract}
The culinary business in the form of a cafe that is mushrooming at this time makes business owners think hard to make their café different from the others so that it can attract customers to come, one of which is Mabar \& Game Coffee. Researchers want to see if there is an influence between service quality on customer satisfaction at Mabar \& Game Coffee. This research uses descriptive quantitative research method with variable $X$ consisting of, variable $X 1$ is physical identity, variable $X 3$ is organizational management, variable X2 is non-physical identity, variable X5 is activity and relationship patterns, variable $X 4$ is quality of results, and variable $Y$ is customer satisfaction. The data analysis technique used is multiple linear regression, calculating the hypothesis using the F test and t test where the F test is to determine the simultaneous effect between the $X$ to $Y$ variables, while the t test is to determine the partial effect of the $X$ to $Y$ variables. SPSS, it was found that variable $X$ which consists of physical identity, nonphysical identity, organizational management, quality of results, activities and relationship patterns have a simultaneous influence on variable $Y$, namely customer satisfaction. Meanwhile, from the calculation using the $t$ test, it was found that nonphysical identity is the most dominant variable, so that according to customers, Mabar \& Game Coffee's non-physical identity greatly affects their satisfaction.

Keywords: service quality, customer satisfaction, cafe
\end{abstract}

PENDAHULUAN

Bisnis kuliner saat ini di negara Indonesia cukup mengalami peningkatan yang pesat, dapat dilihat dari menjamurnya café atau rumah makan bertema minimalis modern yang menjual berbagai macam makanan kekinian. Dengan banyak bermunculan café dengan tema yang sama membuat banyak pelaku usaha memutar otak agar 
cafenya memiliki nilai lebih atau ada sesuatu yang berbeda sehingga mampu menarik perhatian masyarakat untuk dating. Pada umumnya café yang bertema modern mencari target pasar anak muda, sehingga dari harga yang ditawarkan pun tidak terlalu mahal.

Target pasar anak muda bukan tanpa alasan, perkembangan internet yang sangat pesat membuat masyarakat saat ini banyak menggunakan media sosial untuk mencari atau mendapatkan informasi, terutama anak muda. Ditunjang dengan adanya pandemic covid-19, dimana pembelajaran tatap muka diubah menjadi pembelajaran online membuat para anak muda mau tidak mau menyesuaikan diri dengan perkembangan dunia digital yang ada. Media sosial adalah salah satu aplikasi digital yang paling sering dipakai anak muda pada saat ini, mereka dapat mencari informasi mengenai lokasi menarik untuk dikunjungi, salah satunya adalah café.

Menciptakan usaha berupa café atau rumah makan pada situasi seperti ini bukan hal yang gampang, hal ini tidak hanya dipengaruhi oleh banyaknya usaha bertema sama namun juga karena adanya pandemic covid-19 dimana terdapat pembatasan ruang gerak masyarakat, sehingga penurunan jumlah pelanggan merupakan salah satu hal yang tak terhindarkan, termasuk bagi beberapa café yang ada di Sidoarjo, salah satunya adalah Mabar \& Game Coffee, dimana café ini didirikan bertepatan dengan adanya pandemic covid-19 sehingga pemilik café harus memutar otak mencari jalan keluar agar café tetap memiliki banyak pengunjung namun tetap melaksanakan aturan pemerintah untuk mencegah penularan.

Mabar \& Game Coffee berada di lokasi cukup strategis, tidak jauh dari pusat kota Sidoarjo. Pemilik dari café tersebut tidak menginginkan café hanya digunakan sebagai tempat makan dan minum, tapi terdapat sesuatu hal yang membuat pelanggan tertarik, sehingga tercetuslah ide untuk membuat café sebagai tempat untuk bermain game online, dengan dilengkapi wifi yang mumpuni sehingga membuat pelanggan yang dating merasa nyaman. Target dari café tersebut sudah dipastikan adalah anak muda karena pengguna game online saat ini didominasi oleh anak muda, ditunjang karena pembelajaran online dan pembatasan sosial maka banyak anak muda memanfaatkan waktunya untuk berpetualang di dunia digital, salah satunya adalah game online.

Game online saat ini dapat dimainkan secara bersama-sama, sehingga terciptalah kata "mabar" yang berarti "main" dan "bareng", dimana game tersebut dapat dimainkan bersama orang lain sehingga menjadi lebih mudah jika dilakukan dengan berkumpul di satu tempat. Ide dari pemilik café Mabar \& Game Coffee ini ternyata cukup bagus karena baru beberapa hari buka, café ini sudah ramai pengunjung terutama anak muda. Walaupun ada beberapa kali aturan pembatasan dari pemerintah, café ini masih dapat berjalan dengan baik karena banyaknya pelanggan yang datang namun dengan tetap menerapkan protokol Kesehatan.

Kualitas pelayanan suatu tempat usaha salah satunya café memiliki peranan penting untuk menunjang kepuasan pelanggan, karena jika pelanggan merasa puas maka ada kemungkinan pelanggan tersebut akan kembali datang. Dengan adanya permasalahan yang telah dijelaskan diatas, maka peneliti ingin mengetahui adakah pengaruh dari kualitas pelayanan pada kepuasan pelanggan Mabar \& Game Coffee.

\section{KAJIAN LITERATUR}

Jurnal penelitiannya yang berjudul "Pengaruh Pandangan Dimensi Kualitas Layanan Pada Niat Pembelian Ulang", membuktikan bahwa Persepsi Kualitas Layanan yaitu ada 5 (Keandalan, Bukti Langsung, Empati, Daya Tanggap, dan Jaminan) dan Kepuasan pelanggan berpengaruh signifikan terhadap niat pembelian baik secara parsial maupun secara simultan. Sedangkan faktor yang dominan mempengaruhi adalah dimensi empati. Sample diamvil dengan melakukan teknik Purposive Sampling sebanyak 30 
mahasiswa dari total populasi sebanyak 100 mahasiswa. Teknik analisis yang digunakan adalah regresi bertingkat (Wisnalmawati, 2005).

Jurnal penelitiannya yang berjudul "Pengaruh Kepuasan Pelanggan Dengan Penelitian menggunakan Fuzzy Service Quality untuk Melihat tingkat Kualitas Pelayanan", membuktikan bahwa bahwa persepsi kualitas layanan yang terdiri dari tangible, reliability, assurance, responsiveness, empathy dan kepuasan pelanggan berpengaruh signifikan baik secara parsial maupun secara simultan terhadap kualitas pelayanan. Sedangkan faktor yang dominan mempengaruhi adalah dimensi reliability. Teknik analisis yang dipakai adalah regresi berganda (Djunaidi, 2006).

\section{Kualitas Pelayanan}

Terdapat banyak faktor yang memiliki pedan dalam menentukan kualitas, salah satunya menurut Katz (Saleh, 2010), yaitu:

1. Identitas fisik

Mabar \& Game Coffee secara visual tidak memiliki karakter pada nama, warna, dan pilihan font, yang sering digunakan adalah jenis Arial Black dengan berbagai ukuran huruf, Mabar \& Game Coffee memiliki bangunan yang luas, terkesan kokoh seperti cafe yang lain, selain itu penataan kursi dan meja terlihat rapi dan bersih, hal ini disebabkan Mabar \& Game Coffee tergolong masih baru, yaitu berdiri pada tahun 2020, dan penataan kursi dan meja cukup elegan dilengkapi dengan beberapa fasilitas seperti musholla dan toilet.

Mabar \& Game Coffee tidak memiliki lagu maupun instrument sebagai pembentuk karakter. Media komunikasi yang sering digunakan adalah melalui media sosial dan brosur, untuk company profile masih kurang sosialisasi pada masyarakat.

2. Indentitas non fisik

Meliputi filosofi, sejarah, kepercayaan, budaya atau kultur, dan nilai-nilai. Mabar \& Game
Coffee memiliki sejarah tentang berdirinya cafe dimulai dari tahun 2020. Nilai yang terbentuk tentang Mabar \& Game Coffee hingga saat ini adalah café yang lebih banyak dimanfaatkan untuk melakukan kegiatan game online.

3. Kualitas hasil mutu produk dan pelayanan

Mabar \& Game Coffee memberikan produk berupa makanan dan minuman juga tempat yang nyaman untuk sekedar duduk santai ataupun sambal bermain game online.

4. Aktivitas dan pola hubungan

Hubungan antara cafe dengan masyarakat, memiliki respon tanggung jawab sosial, sumber daya manusia dalam organisasi, kualitas komunikasi, pengalaman pelanggan dan juga jaringan. Mabar \& Game Coffee berusaha membangun hubungan yang baik dengan masyarakat, terutama kepada masyarakat sekitar lokasi café, salah satunya dengan meningkatkan kualitas komunikasi untuk para karyawan. Mabar \& Game Coffee memiliki kotak saran di meja kasir namun sepertinya pelanggan masih belum banyak mengetahuinya karena peletakan kotak saran yang tidak terlalu terlihat.

\section{Kepuasan Pelanggan}

Sikap adalah timbul karena adanya stimulus-stimulus (rangsangan) baik itu dari lingkungan sosial maupun kebudayaan. Dengan demikian terjadi interaksi antara individu dengan lingkungan sekitarnya sehingga terjadi proses belajar dan timbulah pengalaman-pengalaman seseorang terhadap lingkungannya serta dari hasil interaksinya baik dengan kelompok lain ataupun di dalam kelompoknya akan tercipta sikap dalam diri individu tersebut. Sikap umum yang diberikan oleh seseorang pada suatu produk atau jasa minimal ada 8 macam yaitu: sikap menerima, sikap curiga, sikap ketergantungan, sikap pura-pura, sikap ragu-ragu, sikap menolak, sikap tidak 
menentu, dan sikap tidak peduli (Moenir, 2000).

Sikap juga merupakan hasil belajar (Vembriarto, 2020). Oleh karena adanya interaksi, maka sikap senantiasa akan bisa berubah, yang oleh Ahmadi (Ahmadi, 2019) disebutkan ada dua faktor yang menyebabkannya, yaitu antara lain:

1. Faktor dari dalam yaitu faktor yang terdapat pada diri seseorang dimana dia dapat menyaring dan mentelaah suatu hal.

2. Faktor dari luar yaitu faktor yang dipengaruhi oleh hubungan sosial kita dengan orang luar.

Kepuasan pelanggan dan ketidakpuasan pelanggan adalah adanya perbedaan antara harapan dan kinerja yang dirasakan oleh pelanggan. Maka kepuasan pelanggan didapat dari hasil kinerja yang sesuai harapan pelanggan (Kotler, 2020). Perusahaan pasti memiliki keinginan untuk memuaskan pelanggan namun bagi pelanggan yang merasa tidak puas, mereka akan berbalik menyerang perusahaan, mulai dari mengembalikan produk yang telah dibeli, menjelek-jelekkan di media, bahkan bisa sampai ke meja hijau. Hal tersebut harus bisa diantisipasi oleh para pemilik usaha salah satunya cafe. Dibawah ini adalah bagan tentang berbagai tindakan konsumen akibat perasaan tidak puas.

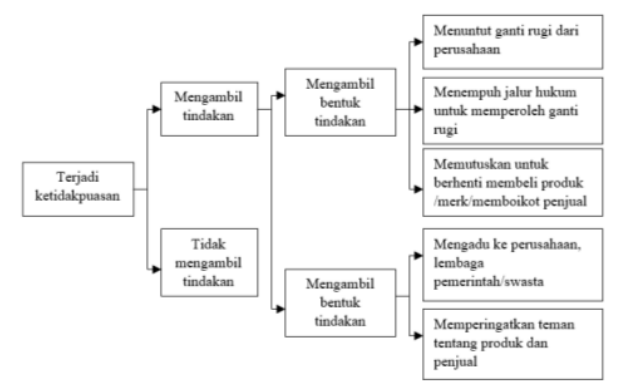

Gambar 1

Tindakan Konsumen Akibat Ketidakpuasan

Sumber : (Kotler, 2020)

Memberikan kepuasan kepada pelanggan dapat memberikan dampak yang positif pada Mabar \& Game
Coffee, terutama untuk jangka panjang. Sedangkan secara konseptual, konsep kepuasan pelanggan adalah seperti gambar berikut.

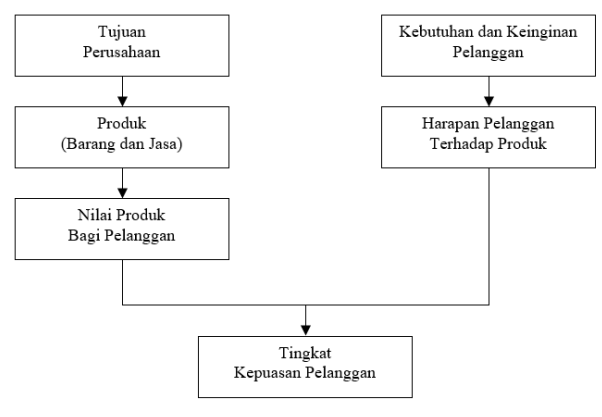

Gambar 2

Model Konseptual Kepuasan Pelanggan Sumber: (Tjiptono, 2012)

\section{METODE PENELITIAN}

Peneliti menggunakan metode penelitian kuantitatif deskriptif dimana untuk menghitung sampel, dapat menggunakan rumus Slovin (Ruslan, 2016) sebagai berikut:

$$
\mathrm{n}=\frac{\mathrm{N}}{1+\mathrm{N} e^{2}}
$$

Keterangan:

n : sampel

$\mathrm{N}$ : populasi

e : persentase ketidaktelitian

Dari rumus tersebut maka sample pada penelitian ini dapat dihitung sebagai berikut:

$$
\begin{aligned}
& \mathrm{n}=\frac{\mathrm{N}}{1+\mathrm{N} e^{2}} \\
& =\frac{5512}{1+5512.0,1^{2}} \\
& =\frac{5512}{1+5512.0,01} \\
& =98,22
\end{aligned}
$$

Dari hasil perhitungan tersebut, hasil yang didapat adalah 98,22 kemudian dibulatkan menjadi 100. Maka pada penelitian ini, responden yang diteliti adalah 100 orang diambil secara accidental dengan cara menemui mereka di Mabar \& Game Coffee. Penelitian secara acak dilakukan dengan mengacak hari penyebaran kuisioner selama bulan Agustus tahun 2021. Dalam proses penyebaran kuisioner ini, 
terdapat beberapa hal diluar dugaan peneliti misalnya isian kuisioner yang tidak lengkap, kuisioner yang hilang, dan kemungkinan responden yang tidak mengembalikan kuisioner kepada peneliti. Untuk menghindari hal-hal tersebut maka peneliti menyebar kuisioner melebihi hasil perhitungan sampel.

Adapun teknik pengumpulan data yang dipakai pada penelitian ini adalah:

a. Kuesioner

Melakukan pembagian kuesioner kepada pelanggan Mabar \& Game Coffee secara acak.

b. Dokumentasi

Mengumpulkan data dari berbagai sumber terutama dari pemilik Mabar \& Game Coffee.

Metode analisis data yang dipakai pada penelitian ini adalah analisa regresi berganda. Analisis regresi berganda dipakai untuk melihat pengaruh secara simultan maupun parsial antara variabel bebas $(\mathrm{X})$ dan variabel terikat $(\mathrm{Y})$. Rumus uji regresi linier berganda adalah sebagai berikut:

$Y=b_{0}+b_{1} X_{1}+b_{2} X_{2}+b_{3} X_{3}+b_{4} X_{4}+b_{5} X_{5}+e$

Keterangan :

$\mathrm{Y}$ : Kriterium atau variabel terikat

$\mathrm{X}_{1} \quad$ : Variabel X1

$\mathrm{X}_{2}$ : V. X2

$\mathrm{X}_{3} \quad$ : V.X3

$\mathrm{X}_{4} \quad: \mathrm{V} . \mathrm{X} 4$

$\mathrm{X}_{5} \quad$ : V.X5

$\mathrm{b}_{1} \quad$ : koefisien prediktor

$\mathrm{b}_{0} \quad$ : konstanta

$e \quad:$ Kesalahan

Dalam regresi linier berganda terdapat uji $\mathrm{F}$ dan uji $\mathrm{t}$ dimana uji $\mathrm{F}$ untuk melihat pengaruh simultan, uji $\mathrm{t}$ untuk melihat pengaruh parsial:

a. Uji F

$$
F=\frac{R^{2} /(K-1)}{\left(1-R^{2}\right)(n-K)}
$$

Keterangan:

F : pendekatan distribusi probabilitas Fisher

$\mathrm{R}$ : koefisien regresi $\mathrm{n}$ : jumlah data (sampel)

b. Uji t

$$
t=\frac{b}{S e b}
$$

Keterangan:

b : koefisien regresi

Seb : Estimasi kesalahan standar b

Perbandingan $\mathrm{t}$ hitung dengan $\mathrm{t}$ tabel (dengan signifikasi 0,05) digunakan untuk mengambil kesimpulan apakah hipotesis dapat diterima. Jika $\mathrm{t}$ hitung tidak lebih besar dari t tabel berarti $\mathrm{Ha}$ diterima, dimana berarti ada pengaruh yang signifikan antara variabel bebas (X) dengan variabel terikat (Y). Begitupun sebaliknya jika t hitung lebih kecil dari t tabel maka Ho ditolak, yang memiliki arti bahwa tidak ada pengaruh yang signifikan antar variabel $X$ dengan variabel Y.

\section{PEMBAHASAN}

Pengolahan data pada penelitian ini menggunakan aplikasi SPSS, untuk mengetahui adakah pengaruh dari variabel X pada variabel Y, dengan hasil hitung sebagai berikut:

Tabel 1

Hasil Analisis Regresi Berganda

\begin{tabular}{cccc}
\hline Variabel & $\begin{array}{r}\text { Koef } \\
\text { Beta }\end{array}$ & $\mathrm{t}_{\text {hit }}$ & sig \\
\hline $\mathrm{X} 1$ & 0,231 & 2,796 & 0,007 \\
\hline $\mathrm{X} 2$ & 0,297 & 4,030 & 0,000 \\
\hline $\mathrm{X} 3$ & 0,229 & 3,059 & 0,004 \\
\hline $\mathrm{X} 4$ & 0,214 & 2,837 & 0,007 \\
\hline $\mathrm{X} 5$ & 0,215 & 2,430 & 0,018 \\
\hline$\alpha$ & $=0,05$ & & \\
$\mathrm{R}$ & $=0,792$ \\
Adjusted & & & \\
$\mathrm{R}$ Square & $=0,593$ \\
F-Hitung & $=29,621$ \\
F-Tabel & $=2,311$ & & \\
Signifikan & $=0,000$ \\
t-tabel & $=1,996$ & & \\
\multicolumn{4}{r}{ Sumber : penghitungan spss }
\end{tabular}

\section{Uji Regresi Secara Simultan}

Uji ini dilakukan untuk mengetahui apakah terdapat pengaruh simultan antara variabel X1 sampai X5 
pada variabel $\mathrm{Y}$, penghitungan regresi secara simultan menggunakan SPSS.

Tabel 2

Hipotesis Secara Simultan

\begin{tabular}{|c|c|c|}
\hline Hipotesis & Nilai & $\begin{array}{l}\text { Kepu } \\
\text { tusan }\end{array}$ \\
\hline $\mathrm{H}_{0}: \beta_{i}=0$ & $=$ & Tolak \\
\hline $\mathrm{X} 1, \mathrm{X} 2, \mathrm{X} 3, \mathrm{X} 4$ & 29,621 & $\mathrm{H}_{0}$ \\
\hline $\mathrm{X} 5 \neq \mathrm{Y}$ & $\begin{array}{l}\text { sig }= \\
0,000\end{array}$ & \\
\hline $\mathrm{H}_{\mathrm{a}}: \beta_{i} \neq 0$ & $\mathrm{~F}_{\text {tabel }}=$ & \\
\hline $\mathrm{X} 1, \mathrm{X} 2, \mathrm{X} 3, \mathrm{X} 4$ & 2,321 & \\
\hline $\mathrm{X} 5=\mathrm{Y}$ & & \\
\hline $\mathrm{Y}, \alpha=0,05$ & & \\
\hline
\end{tabular}

Dari hasil penghitungan diatas maka dapat diambil kesimpulan bahwa Ho ditolak dan Ha diterima yang berarti bahwa variabel $\mathrm{X} 1$ adalah identitas fisik, variabel $\mathrm{X} 3$ adalah manajemen organisasi, variabel X2 adalah identitas non fisik, variabel X5 adalah aktivitas dan pola hubungan, variabel $\mathrm{X} 4$ adalah kualitas hasil, memiliki pengaruh pada variabel $Y$ yaitu kepuasan pelanggan.

\section{Menentukan Variabel Paling Dominan}

Cara untuk mengetahui variabel mana yang paling dominan adalah menggunakan uji $\mathrm{t}$ yang dihitung menggunakan SPSS.

Tabel 3

Ringkasan Hasil Regresi

\begin{tabular}{ccc}
\hline Variabel & $\begin{array}{c}\text { Koefi } \\
\text { sien } \\
\text { Beta }\end{array}$ & Pengaruh \\
\hline X1 & 0,231 & Sig. \\
\hline X2 & 0,297 & Sig. \\
\hline X3 & 0,229 & Sig. \\
\hline X4 & 0,214 & Sig. \\
\hline X5 & 0,215 & Sig. \\
\hline
\end{tabular}

Sumber : hasil penghitungan SPSS

Berdasarkan pada tabel diatas, variabel X2 yaitu identitas non fisik memiliki pengaruh yang paling besar terhadap variabel $Y$ yaitu kepuasan pelanggan.
Uji Model Regresi Secara Parsial

Uji model regresi secara parsial digunakan menggunakan uji $\mathrm{t}$ dimana kita dapat melihat apakah setiap variabel $\mathrm{X}$ memiliki pengaruh terhadap $\mathrm{Y}$.

\section{Variabel X1 (Identitas Fisik)}

Dari tabel hasil analisis regresi bergenda, pengujian hipotesis koefisien regresi variabel X1 (identitas fisik) dapat dituliskan dalam tabel dibawah ini:

Tabel 4

Hipotesis Variabel X1

\begin{tabular}{lll}
\hline Hipotesis & \multicolumn{1}{c}{ Nilai } & $\begin{array}{c}\text { Keputus } \\
\text { an }\end{array}$ \\
\hline $\mathrm{H}_{0}: \beta_{1}=0$ & $\mathrm{t}=$ & Tolak \\
$\mathrm{X} 1 \neq \mathrm{Y}$ & 2,796 & $\mathrm{H}_{0}$ \\
& sig $=$ \\
$\mathrm{H}_{\mathrm{a}}: \beta_{1} \neq 0$ & 0,007 \\
$\mathrm{X} 1=\mathrm{Y}$ & $\mathrm{t}_{\text {tabel }}=$ \\
$\alpha=0,05$ & 1,996
\end{tabular}

Sumber : hasil penghitungan SPSS

Dari hasil penghitungan tabel tersebut dapat diartikan bahwa $\mathrm{Ha}$ diterima dimana terdapat pengaruh antara identitas fisik terhadap kepuasan pelanggan.

\section{Variabel X2 (Identitas Non Fisik)}

Dari tabel hasil analisis regresi bergenda, pengujian hipotesis koefisien regresi variabel X2 (identitas non fisik) dapat dituliskan dalam tabel dibawah ini:

Tabel 5

Hipotesis Variabel X2

\begin{tabular}{lll}
\hline \multicolumn{1}{c}{ Hipotesis } & \multicolumn{1}{c}{ Nilai } & \multicolumn{1}{c}{$\begin{array}{c}\text { Keput } \\
\text { usan }\end{array}$} \\
\hline $\mathrm{H}_{0}: \beta_{2}=0$ & $\mathrm{t}=4,030$ & Tolak \\
$\mathrm{X} 2 \neq \mathrm{Y}$ & sig $=0,000$ & $\mathrm{H}_{0}$ \\
& $\mathrm{t}_{\text {tabel }}=$ \\
$\mathrm{H}_{\mathrm{a}}: \beta_{2} \neq 0$ & 1,996 \\
$\mathrm{X} 2=\mathrm{Y}$ \\
$\alpha=0,05$ \\
\hline \multicolumn{3}{c}{ Sumber : Hasil penghitungan SPSS } \\
\multicolumn{3}{c}{ Dari hasil penghitungan tabel } \\
tersebut dapat diartikan bahwa Ha \\
diterima dimana terdapat pengaruh
\end{tabular}


Jurnal Ilmu Komunikasi, Vol.8 No.2 September 2021

antara identitas non fisik terhadap kepuasan pelanggan.

\section{Variabel X3 (Manajemen Organisasi)}

Dari tabel hasil analisis regresi bergenda, pengujian hipotesis koefisien regresi variabel X3 (manajemen organisasi) dapat dituliskan dalam tabel dibawah ini:

Tabel 6

Hipotesis Variabel X3

\begin{tabular}{|c|c|c|}
\hline Hipotesis & Nilai & $\begin{array}{l}\text { Kepu } \\
\text { tusan }\end{array}$ \\
\hline $\mathrm{H}_{0}: \beta_{3}=0$ & $\mathrm{t}$ & Tola \\
\hline$X 3 \neq Y$ & $\begin{array}{l}3,059 \\
\operatorname{sig}=\end{array}$ & $\mathrm{k} \mathrm{H}_{0}$ \\
\hline $\mathrm{H}_{\mathrm{a}}: \beta_{3} \neq 0$ & 0,004 & \\
\hline $\begin{array}{l}\mathrm{X} 3=\mathrm{Y} \\
\alpha=0,05\end{array}$ & $\mathrm{t}_{\text {tabel }}=$ & \\
\hline
\end{tabular}

Sumber : Hasil penghitungan SPSS

Dari hasil penghitungan tabel tersebut dapat diartikan bahwa $\mathrm{Ha}$ diterima dimana terdapat pengaruh antara manajemen organisasi terhadap kepuasan pelanggan.

\section{Variabel X4 (Kualitas Hasil)}

Dari tabel hasil analisis regresi bergenda, pengujian hipotesis koefisien regresi variabel X4 (kualitas hasil) dapat dituliskan dalam tabel dibawah ini:

Tabel 7

Hipotesis Variabel X4

\begin{tabular}{lll}
\hline \multicolumn{1}{c}{ Hipotesis } & \multicolumn{1}{c}{ Nilai } & \multicolumn{1}{c}{$\begin{array}{c}\text { Kepu } \\
\text { tusan }\end{array}$} \\
\hline $\mathrm{H}_{0}: \beta_{4}=0$ & $\mathrm{t}=2,837$ & Tolak \\
$\mathrm{X} 4 \neq \mathrm{Y}$ & sig $=0,007$ & $\mathrm{H}_{0}$ \\
& $\mathrm{t}_{\text {tabel }}=$ & \\
$\mathrm{H}_{\mathrm{a}}: \beta_{4} \neq 0$ & 1,996 \\
$\mathrm{X} 4=\mathrm{Y}$ & & \\
$\alpha=0,05$ & & \\
\hline
\end{tabular}

Sumber : Hasil penghitungan SPSS

Dari hasil penghitungan tabel tersebut dapat diartikan bahwa $\mathrm{Ha}$ diterima dimana terdapat pengaruh antara kualitas hasil terhadap kepuasan pelanggan.

\section{Variabel X5 (Aktivitas dan Pola Hubungan)}

Dari tabel hasil analisis regresi bergenda, pengujian hipotesis koefisien regresi variabel X5 (aktivitas dan pola hubungan) dapat dituliskan dalam tabel dibawah ini:

Tabel 8

Hipotesis Variabel X5

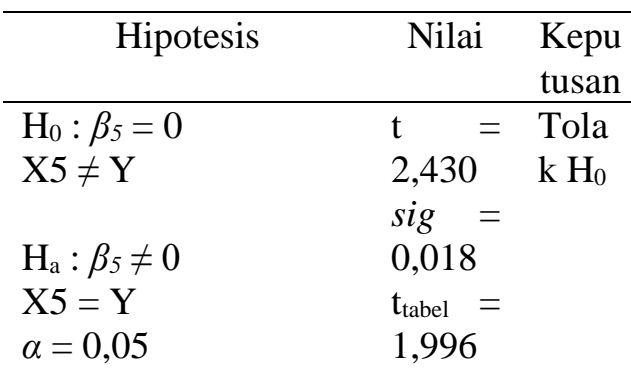

Sumber : Hasil penghitungan SPSS

Dari hasil penghitungan tabel tersebut dapat diartikan bahwa $\mathrm{Ha}$ diterima dimana terdapat pengaruh antara aktivitas dan pola hubungan terhadap kepuasan pelanggan.

Berdasarkan penghitungan SPSS yang telah dilakukan dengan pengujian hipotesis, menunjukkan bahwa pelanggan merasa sangat puas dengan pelayanan yang diberikan oleh Mabar \& Game Coffee. Hal ini tidak dapat dipungkiri karena jumlah pengunjung yang datang pun cukup banyak apalagi jika dikaitkan dengan pandemi covid-19 yang pada umumnya mengalami penurunan cukup pesat, justru Mabar \& Game Coffee dapat mempertahankan eksistensinya.

Tingginya jumlah pelanggan tidak dapat dipungkiri merupakan hasil jerih payah dari CEO Mabar \& Game Coffee yang berjuang keras agar masyarakat mengenal dan dapat menerima kehadiran café tersebut. Berbagai upaya dilakukan, selain dengan iklan yang dilakukan di berbagai media sosial, kualitas karyawan yang selalu ditingkatkan, dan juga CEO terjun langsung ke lapangan memantau setiap perkembangan yang terjadi di Mabar \& Game Coffee, dan tidak segan-segan untuk menerima keluhan pelanggan, maka dari itu tidak aneh jika Mabar \& 
Game Coffee banyak diminati oleh anak muda walaupun usia café dapat dibilang masih belum terlalu lama berdiri dengan banyak pesaing mengingat café tersebut terletak tidak jauh dari pusat kota Sidoarjo.

Fasilitas yang diberikan oleh Mabar \& Game Coffee sudah sangat baik terutama disediakannya musholla dan toilet, selain itu kebersihan sangat terjaga, sehingga pelanggan merasa nyaman berada di café tersebut. Selain pelayanan yang baik, Mabar \& Game Coffee juga sering melakukan pertandingan game online dengan banyak hadiah menarik sehingga banyak pelanggan terutama anak muda yang tertarik untuk datang.

\section{PENUTUP}

Berdasarkan hasil penghitungan dan uji yang telah dilakukan menggunakan regresi linier berganda, juga uji hipotesis menggunakan rumus statistik yang dihitung dengan SPSS maka hasil penelitian yang dilakukan terhadap pelanggan Mabar \& Game Coffee, penulis menarik kesimpulan bahwa komponen kualitas pelayanan berupa identitas fisik, penampilan cafe dan kenyamanan Mabar \& Game Coffee secara simultan dan parsial berpengaruh pada kepuasan pelanggan. Adanya pengaruh secara simultan ini menunjukkan bahwa kelima variabel dapat menjadi penentu tinggi rendahnya pengaruh kualitas pelayanan Mabar \& Game Coffee terhadap kepuasan pelanggan.

Dari hasil analisis data yang telah dihitung menggunakan SPSS menunjukkan bahwa variabel identitas non fisik adalah variabel yang paling dominan dari kualitas pelayanan yang mempengaruhi kepuasan pelanggan. Dari kelima komponen kualitas pelayanan yaitu identitas fisik, aktivitas dan pola hubungan, manajemen organisasi, identitas non fisik, kualitas hasil, maka yang paling berpengaruh terhadap kepuasan pelanggan adalah melalui identitas non fisik Mabar \& Game Coffee.

Dari hasil penghitungan dan analisis data, maka penulis ingin memberikan beberapa saran kepada Mabar \& Game Coffee, uaitu:

1. Kualitas pelayanan dipengaruhi oleh lima hal yaitu kualitas hasil, identitas fisik, aktivitas dan pola hubungan, identitas non fisik, manajemen organisasi. Sehingga walau hasil dari analisis data menunjukkan pelanggan puas dengan pelayanan yang diberikan namun diharapkan CEO Mabar \& Game Coffee dapat lebih menambahkan pelayanan agar pelanggan semakin memiliki keinginan untuk datang atau berkunjung kembali.

2. Dari analisis yang dilakukan menunjukkan bahwa variabel identitas non fisik adalah variabel yang paling dominan pada kualitas pelayanan yang sangat berpengaruh pada kepuasan pelanggan maka diharapkan Mabar \& Game Coffee lebih memperhatikan item-item dari variabel identitas non fisik, seperti memberikan pelatihan kepada karyawan agar dapat melakukan komunikasi yang baik pada pelanggan.

3. Walau pendapat pelanggan cukup bagus dilihat dari hasil kuesioner, namun diharapkan Mabar \& Game Coffee tidak merasa puas dan berhenti meningkatkan kualitas pelayanan, karena persaingan di dunia bisnis terutama café sangat tinggi, sehingga banyak pesaing diluar sana yang mungkin akan mengadopsi apa yang telah Mabar \& Game Coffee lakukan.

\section{REFERENSI}

Ahmadi, A. (2019). Psikologi Sosial. Rineka Cipta.

Arikunto. (2012). Prosedur Penelitian Suatu Pendekatan Pendekatan Praktek (edisi revisi). PT Rineka Cipta.

Djunaidi. (2006). Analisa Kepuasan Pelanggan Dengan Penelitian Fuzzy Service Quality Dalam Upaya Meningkatkan Kualitas Pelayanan. Jurnal Ilmiah Teknik Industri, 4(3), 139-146.

Kotler, P. (2020). Prinsip-Prinsip 
Pemasaran. Erlangga.

Moenir, A. . (2000). Manajemen Pelayanan Umum. Bumi Aksara.

Ruslan, R. (2016). Manajemen Public Relations dan Media Komunikasi, Konsepsi dan Aplikasi. Raja Grafindo Persada.

Saleh, A. M. (2010). Public Service Communication. UMM Press.

Sugiyono. (2018). Metode Penelitian Kuantitatif Kualitatif dan $R \& D$. Alfabeta.

Tjiptono, F. (2012). Manajemen Jasa. Andi Offset.

Vembriarto. (2020). Psikologi Sosial Suatu Pengantar Ringkas. Yayasan Pendidikan Paramita.

Wisnalmawati. (2005). Pengaruh Persepsi Dimensi Kualitas Layanan Terhadap Niat Pembelian Ulang. Jurnal Ekonomi \& Bisnis, $3(10)$.

\section{BIODATA PENULIS}

Rosiana Andhikasari menempuh pendidikan S1 jurusan ilmu komunikasi, FISIP, Universitas Brawijaya Malang, dan menempuh pendidikan S2 jurusan magister ilmu komunikasi, Universitas Budi Luhur Jakarta. Menjadi dosen pengajar di Fakultas Komunikasi dan Bahasa, Universitas Bina Sarana Informatika mulai tahun 2017 hingga saat ini. 